39. Fingerendgelenkluxation mit Strecksehnenverletzung

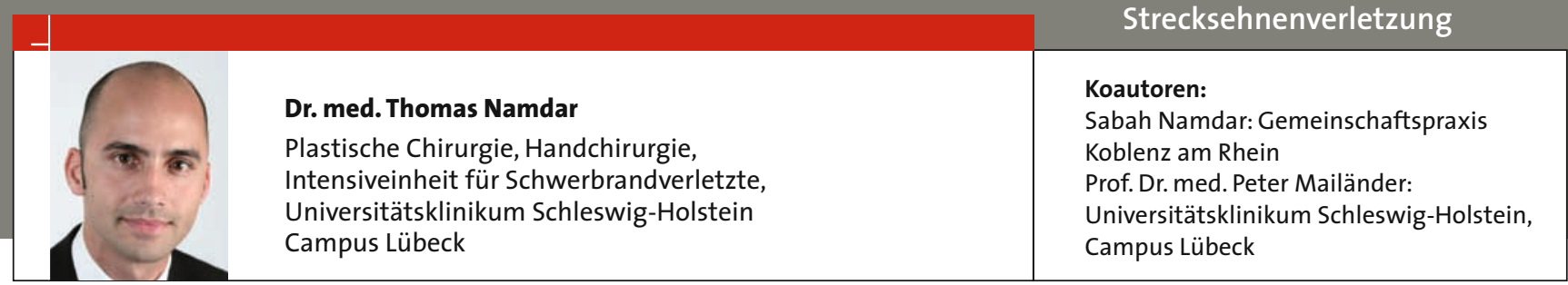

\title{
Bagatellverletzungen der Hand
}

\section{Kleine Ursache - gravierende Folgen}
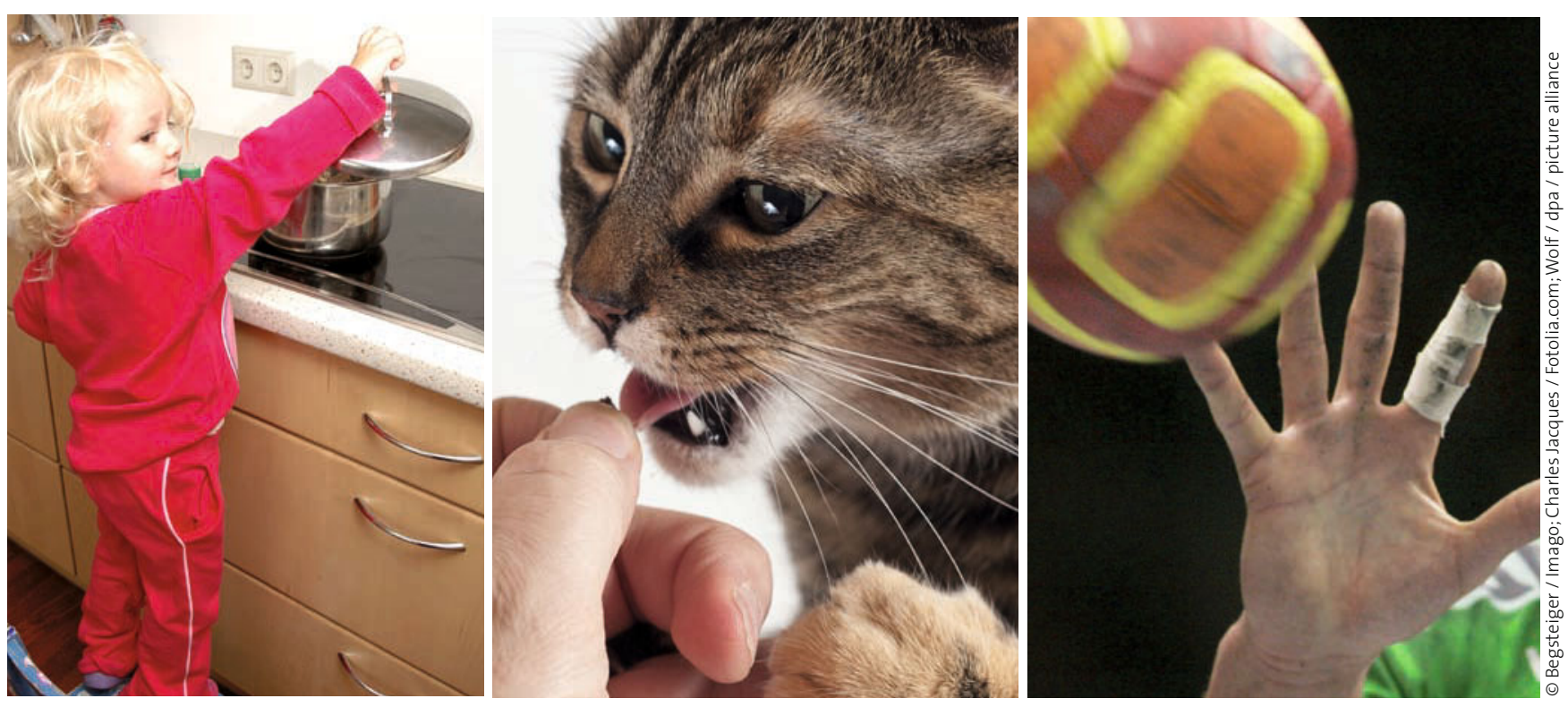

- Die menschliche Hand ist einzigartig in ihrer Anatomie und Funktion. Aufgrund ihrer exponierten Position kommt es häufig zu Verletzungen der Hand, der Finger oder auch der Arme. So stellen Patienten mit Verletzungen der Hand ein großes Patientenkollektiv in Arztpraxen und Notaufnahmen von Krankenhäusern dar. Doch nicht selten wird eine scheinbar geringfügige Handverletzung falsch eingeschätzt. Ein Grund hierfür scheint die allgemeine Erfahrung zu sein, dass derartige „Bagatellverletzungen“ regelhaft ohne großen Behandlungsaufwand und folgenlos ausheilen.

\section{Unterschätzen Sie die Verletzung nicht!}

Konsultiert ein handverletzter Patient einen Arzt, so muss sich dieser der besonderen Situation bewusst sein. Denn die Fehlinterpretation einer Verletzung der Hand kann für das berufliche und private Leben des Patienten folgenreich sein. Die Gefahr, eine Verletzung funktioneller Strukturen unmittelbar nach dem Trauma zu unterschätzen ist hoch. Zudem ist es nicht einfach, die
Auswirkungen der Verletzung auf die berufliche Tätigkeit des Patienten richtig einzuordnen.

Funktionelle Strukturen (Muskeln, Sehnen, Bänder, Gefäße, Nerven, Knochen) liegen in der Hand auf engstem Raum zusammen. Nur das perfekte Zusammenspiel aller Komponenten ermöglicht es dem Menschen die Hand in ihrem gesamten Funktionsumfang und mit voller Kraft und Ausdauer einzusetzen. Je nach beruflicher Tätigkeit (Handwerker, Musiker, Programmierer) werden der Hand unterschiedlichste Anforderungen abverlangt. Insbesondere im Kindesalter können Verletzungen die altersgerechte Entwicklung der Hand behindern. Die rechtzeitige und adäquate operative Versorgung von Handverletzungen und die optimale interdisziplinäre postoperative Behandlung (Hausarzt, Handchirurg, Physiotherapeut) sind deshalb entscheidend für die Handfunktion. Nur bei einem reibungslosen Therapieablauf und engem Kontakt zwischen niedergelassenen und klinisch tätigen Ärzten kann ein optimaler Therapieerfolg erzielt werden und die damit verbundenen sozioökonomischen Kosten so gering wie möglich gehalten werden. 